\title{
Cry Features Reflect Pain Intensity in Term Newborns: An Alarm Threshold
}

\author{
CARLO V. BELLIENI, RENATA SISTO, DUCCIO M. CORDELLI, AND GIUSEPPE BUONOCORE
}

Department of Pediatrics, Obstetrics and Reproductive Medicine, University of Siena, 53100 Siena, Italy [C.V.B., D.M.C., G.B.], and ISPESL, Department of Occupational Health, Monteporzio Catone, Rome, Italy [R.S.]

\begin{abstract}
ABSTR
The purpose of this study was to assess differences in sound
spectra of crying of term newborns in relation to different pain
levels. Fifty-seven consecutively born neonates were evaluated
during heel-prick performed with different analgesic techniques.
Crying was recorded and frequency spectrograms analyzed. A
pain score on the DAN (Douleur Aiguë du Nouveau-né) scale
was assigned to each baby after the sampling. Three features
were considered and correlated with the corresponding DAN
scores: 1 ) whole spectral form; 2 ) the fundamental frequency of
the first cry emitted ( $\left.\mathrm{F}_{0}\right)$; and 3 ) root mean square sound pressure
normalized to its maximum. After emission of the first cry,
babies with DAN scores $>8$, but not with DAN scores $\leq 8$ ( $p<$
0.001), showed a pattern ("siren cry") characterized by a se-
quence of almost identical cries with a period on the order of $1 \mathrm{~s}$.
A statistically significant correlation was found between root
mean square ( $\left.r^{2}=89 \%, p<0.01\right)$, $\mathrm{F}_{0}\left(r^{2}=32 \%, p<0.05\right)$,
\end{abstract}
siren cry $\left(r^{2}=68.2 \%, p=0.02\right)$, and DAN score. $\mathrm{F}_{0}$ did not show significant correlation with DAN score in the subset of neonates with DAN scores $\leq 8\left(r^{2}=1.4 \%, p=0.94\right)$, and babies with a DAN score $>8$ had a significantly higher $\mathrm{F}_{0}$ than those with lower DAN scores $(p=0.016)$. An alarm threshold exists between high $(>8)$ and low $(\leq 8)$ DAN scores: crying has different features in these two groups. When pain exceeds a DAN score of 8 , usually a first cry at a high pitch is emitted, followed by the siren cry, with a sound level maintained near its maximum. (Pediatr Res 55: 142-146, 2004)

RMS, root mean square

\section{Abbreviations}

$\mathbf{F}_{\mathbf{0}}$, fundamental sound frequency

DAN, Douleur Aiguë du Nouveau-Né

SS, sensorial saturation
Crying is simultaneously a sign, symptom, and signal (1). It is the infant's earliest form of communication, but the significance and meaning of neonatal crying are still unclear (2) because different crying features do not reflect different causes (e.g. hunger, pain, and fussiness) (3), but different degrees of distress (4-6), so that gradations of crying may help a listener to narrow down the range of possible causes, but only with the help of contextual information $(4,6-9)$. In the last few years, pain scales have been developed to discriminate levels of pain suffered by newborns (10-15), but when analyzing crying, the level of the pain that provoked it is rarely considered (16). The aim of this study was to investigate to what extent crying features vary with the level of pain. To achieve this goal, we studied cry frequency spectrograms at different pain levels expressed by a validated pain scale.

Received December 3, 2002; accepted May 12, 2003

Correspondence: C.V. Bellieni, M.D., U.O. Terapia Intensiva Neonatale, Università degli Studi di Siena, Policlinico "Le Scotte", Viale Mario Bracci,16, 53100 Siena, Italy; e-mail: bellieni@iol.it

Supported by grants from the Italian Ministry for the University and ScientificTechnological Research (MIUR 2001).

DOI: 10.1203/01.PDR.0000099793.99608.CB

\section{METHODS}

\section{Subjects}

This report is based on analysis of a cohort of 57 newborns extrapolated from a previous study (17) consisting of 120 healthy term infants who underwent heel-prick for neonatal screening. Inclusion criteria were Apgar score at least 9 at 5 min, gestational age 38-41 wk, age more than $48 \mathrm{~h}$, and more than $2 \mathrm{~h}$ since last meal. During heel-prick, different analgesic procedures were used, namely SS, SS without oral sugar, oral sugar, sucking, and oral sugar plus sucking. These analgesic procedures were chosen to assess whether SS, a multisensorial stimulation consisting of massage, scent, sweet taste, and human voice $(17,18)$, was more effective than isolated use of oral glucose or sucking. A video of about 1 min was made for each neonate to record behavior and cry. A composite measure of neonatal pain, ranging from 0 to 10 (DAN scale; Table 1) (19), based on facial expression and behavior, was attributed to the babies by the same double-blinded scorer. Siena University Ethical Board approved the present study. Informed consent was obtained from the parents of babies enrolled. 
Table 1. Measure Score*

\begin{tabular}{ll}
\hline Facial expressions & 0 \\
Calm & 1 \\
Snivels and alternates gentle eye opening and closing & \\
Determine intensity of one or more of eye squeeze, brow bulge, & \\
nasolabial furrow: & 2 \\
$\quad$ Mild, intermittent with return to calm & 3 \\
$\quad$ Moderate & 4 \\
$\quad$ Very pronounced, continuous & 0 \\
Limb movements & \\
Calm or gentle movements & \\
Determine intensity of one or more of the following signs: \\
pedals, toes spread, legs tensed and pulled up, agitation of \\
arms, withdrawal reaction: \\
$\quad \begin{array}{l}\text { Mild, intermittent with return to calm } \\
\quad \text { Moderate }\end{array}$ \\
$\quad$ Very pronounced, continuous \\
Vocal expression \\
$\begin{array}{l}\text { No complaints } \\
\text { Moans briefly; for intubated child, looks anxious or uneasy }\end{array}$ \\
$\begin{array}{l}\text { Intermittent crying; for intubated child, gesticulations of } \\
\text { intermittent crying }\end{array}$ \\
$\begin{array}{l}\text { Long-lasting crying, continuous howl; for intubated child, } \\
\text { gesticulations of continuous crying }\end{array}$ \\
\hline
\end{tabular}

* Douleur Aiguë du Nouveau-né.

\section{Procedure}

The digital acoustic signal was extracted from the original. AVI file using GoldWave version 5 beta (GoldWave Inc, St. John's NF, Canada) software, and the waveforms of cries were visualized. The data were converted to ASCII format and analyzed with special software (Labview 5.1; National Instruments Co, Austin, TX, U.S.A.) for cry analysis. The acoustic signals were sampled at $44.1 \mathrm{kHz}$ corresponding to a Nyquist frequency of $22.05 \mathrm{kHz}$. The frequency response and sensitivity of the camcorder microphone are adequate for this kind of analysis, because signal level is high, and sensitivity loss at very high frequency is not a problem for detecting the fundamental frequency or evaluating the normalized amplitude of the signal, which were the quantitative indicators used in this study. A digitized 25-s file was extracted from each record, starting immediately after the heel-prick.

The cry signals were further time-frequency analyzed by short-time Fourier transform, a standard time-frequency analysis technique that provides information about the time evolution of the spectral composition of a complex signal. The 25-s files were divided into $1024\left(2^{10}\right)$ time intervals, each of 23.22 ms. The power spectrum of the signal was computed for each interval to give a time sequence of 1024 spectra for each neonate, with a time resolution of $23.22 \mathrm{~ms}$ and a frequency resolution of $43 \mathrm{~Hz}$.

\section{Measurements}

RMS normalized pressure. RMS values are commonly used for physical quantities that oscillate and have an average of zero, like pressure in a sound wave. RMS acoustic pressure normalized to its maximum is not a measure of absolute cry intensity, but rather a measure of constancy of emission; it measures the fraction of the observation time during which the signal amplitude is near its maximum. To determine RMS value, three mathematical operations are carried out on the function representing the oscillating waveform:

1. The square of the waveform function is determined.

2. The function resulting from step 1 is averaged over time.

3 . The square root of the function resulting from step 2 is determined.

Before step 1 we divided pressure by its maximum absolute value to obtain a normalized pressure waveform. Problems arising from absolute signal amplitude evaluation, which is a function of the microphone-to-neonate distance, were avoided in this way.

First-cry $\boldsymbol{F}_{\boldsymbol{0}} \cdot \mathrm{F}_{0}$ is the base frequency of harmonic vibration of the vocal cords, and it is usually heard as the pitch of the cry $(7,20)$. To determine it, we analyzed the first burst of crying after heel-prick for each neonate with the short-time Fourier transform technique.

Siren cry. We defined "siren cry" as a pattern in which the fundamental frequency and its multiple frequencies were modulated periodically for a continuous time interval of at least $10 \mathrm{~s}$, with a period of about $1 \mathrm{~s}$. In other words, it is an insistent, periodic cry.

\section{Statistical Analysis of Cry Features in Relation to DAN Score}

Statistical analysis was performed by GraphPad Instat, version 3.0 for Windows (GraphPad Software, San Diego, CA, U.S.A.). The RMS normalized pressure of the cry signal, first-cry $\mathrm{F}_{0}$ of each neonate, and the presence of siren cry were compared with DAN scores by linear regression analysis. Data corresponding to DAN $\leq 3$ were not considered, because when the DAN score is very low the neonates rarely cry. First-cry $\mathrm{F}_{0}$ was compared between the populations of neonates with and without siren cry (DAN score $>8$ and $\leq 8$, respectively) by $t$ test (significance criterion, $p<0.05$ ). We also looked for statistical correlations between the different analgesic treatments and cry variables.

\section{RESULTS}

The RMS $\left(r^{2}=89 \%, p<0.01\right)$ and $\mathrm{F}_{0}\left(r^{2}=32 \%, p<0.05\right)$ values, as well as the presence of siren cry $\left(r^{2}=68.2 \%, p<\right.$ $0.05)$, showed a statistically significant correlation with DAN score (Fig. 1). The siren pattern was not present in any cry of the 36 babies with DAN $\leq 8$, whereas it was present in 13 of the 21 babies with DAN $>8(p<0.001)$.

A statistically significant difference in $\mathrm{F}_{0}$ between the two groups (DAN $\leq 8$ and $>8$ ) was found; in fact $\mathrm{F}_{0}$ showed a shift to higher frequencies in neonates with higher DAN: the group with DAN $>8$ had a mean $\mathrm{F}_{0}$ of $630 \pm 330 \mathrm{~Hz}$, whereas that of the other group was $400 \pm 240 \mathrm{~Hz}(p=0.016)$. The first-cry $\mathrm{F}_{0}$ did not show significant correlation with DAN score in the subset of neonates with DAN scores $\leq 8\left(r^{2}=1.4 \%, p=0.94\right.$; Fig. 2).

Significantly different normalized RMS amplitudes were found among the control group and two analgesic groups: oral sugar plus sucking $(p<0.01)$ and SS $(p<0.0005)$. We did not find any statistically significant correlation between $\mathrm{F}_{0}$ or RMS and the analgesic groups. The absence of crying in four of nine 


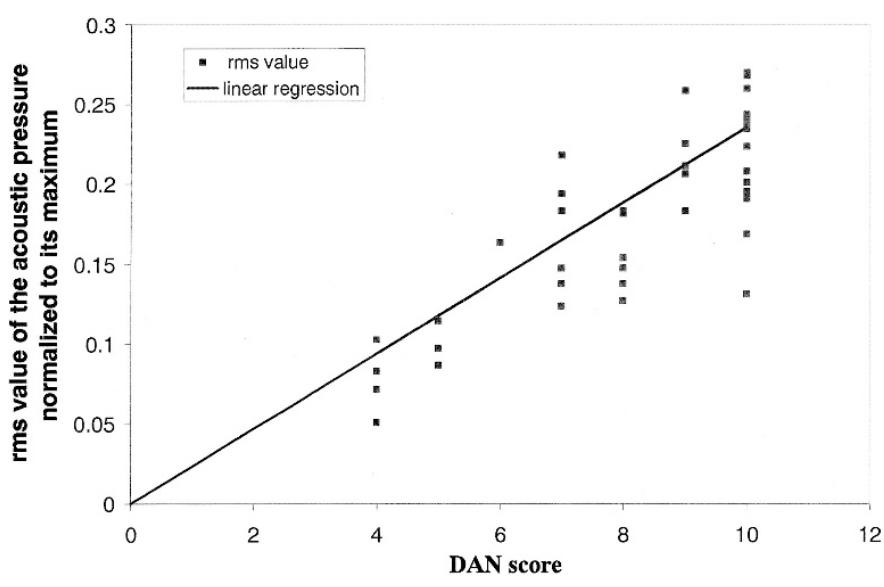

Figure 1. RMS normalized sound pressure during a 25 -s cry sequence plotted against DAN score showing statistically significant correlation $\left(r^{2}=89 \%, p<\right.$ $0.01)$. RMS measures the fraction of the observation time during which the signal amplitude is near its maximum.

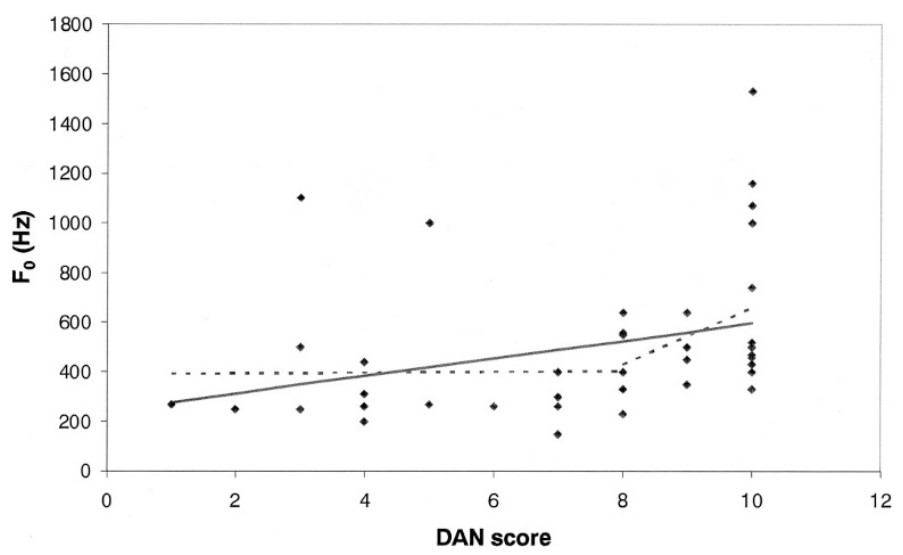

Figure 2. $\mathrm{F}_{0}$ plotted against DAN score $\left(r^{2}=32 \%, p<0.05\right)$. The solid line is a linear regression of all the data; the dotted line represents two separate linear regressions of two data subsets for DAN 0-8 $(A)$ and DAN 9-10 $(B)$. $\mathrm{F}_{0}$ did not show significant correlation with DAN score in the subset of neonates with DAN scores $\leq 8\left(r^{2}=0.14 \%, p=0.94\right)$.

babies of the SS group, three of 10 in the oral sugar plus sucking group, and two of eight in the oral sugar group may have influenced these results. The occurrence of siren cry was not significantly different in analgesic groups and the control group; however siren cry was found in all groups except SS and oral sugar plus sucking; the oral sugar and SS without oral sugar groups had the highest fraction of babies with siren cry (six of 11 and four of 10 , respectively).

\section{DISCUSSION}

It has been proposed that neonatal crying could be a form of protolanguage (21), and many attempts have been made to interpret it. In the 1960s it was suggested that newborns could cry in different ways depending on the cause (22-24), but in the last few years an alternative hypothesis has been proposed: crying is a graded signal $(5,25,26)$, and its features do not depend on the cause, but on the intensity of the distress of the infant. Cry features change in relation to motivational state. In analyzing crying caused by pain, the existence of various levels of pain must be recognized $(10,27)$, and pain intensity must be measured with a validated pain scale. It is an oversimplification to consider generic "pain-induced crying" (2834 ) because pain has various levels reflected by graded crying $(4,5)$. Some interesting attempts have been made to correlate features of crying with pain level, but pain was measured in a subjective manner [e.g. rated by parents, presumed from the type of stimulus (5)], and never with a validated pain scale (33-35).

Only Johnston and Strada (36) looked for a correlation between $\mathrm{F}_{0}$ and a validated pain scale, but they only studied 18 cases in a subgroup of 25 premature babies; the babies had different postconceptual ages, and cry features are known to change with this factor (37). Johnston and Strada (36) found no correlation between $\mathrm{F}_{0}$ or duration of crying and pain score.

Other studies into the relation between crying and pain did not consider the various levels of pain, and some analyzed very few neonates $(38,39)$ or only the first few seconds of crying $(5$, $40,41)$. The present study endeavored to cover all these aspects: we studied only full-term babies, as previous studies showed that crying features change with postconceptual age (37). We did not limit our analysis to $F_{0}$, as features of crying as a whole have been shown to affect adults' judgment of pain intensity (3). We used a relatively large sample of infants. We not only examined the first few seconds of crying and the intensity of crying, but also the extent to which it remained near its maximum, as crying is a dynamic event and the manner in which cry sounds change during longer episodes or bouts is still relatively unexplored, with some exceptions (42). We also studied the time course of crying intensity.

Our results show that pain intensity (DAN score) was correlated with normalized RMS sound pressure. In other words, the stationary character of overall cry intensity increased with increasing pain. However, the most interesting finding in the present study was the regularity and stereotyped pattern of cries with a DAN score $>8$ : above this threshold, the features and presumed meaning of crying changed dramatically. For DAN $\leq 8$, crying was less regular in the modulation of the fundamental frequency and moanlike. When DAN was $>8$, a stereotyped cry was produced, the regularity and repetition of which suggested a call for attention and help. The spectrogram shown in Figure 3 is typical of high-DAN cries: after a few seconds of intense, irregular, and continuous sound, a periodic pattern starts, made up of repeated cries of almost the same duration (on the order of 1s) and spectral composition, separated by very short, quieter intervals. Each cry had a symmetrically modulated fundamental frequency. This was the pattern we called siren cry. Continuous repetition of the same sound signal seems an effective way of alerting the listener. Internal modulation makes each single cry more noticeable, and immediate repetition communicates a sense of alarm. Similar repeated sound patterns, in the same frequency range, are used in different human cultures for communicating alarm (sirens, alarm bells, tom-toms). It is interesting that all cries with a DAN score $\leq 8$ (Fig. 4) lack the periodic pattern shown in Figure 3.

First-cry $\mathrm{F}_{0}$ showed a statistically significant difference between newborns with a DAN score $\leq 8$ and those with a DAN score $>8$. This indicates that when pain exceeds a DAN score 


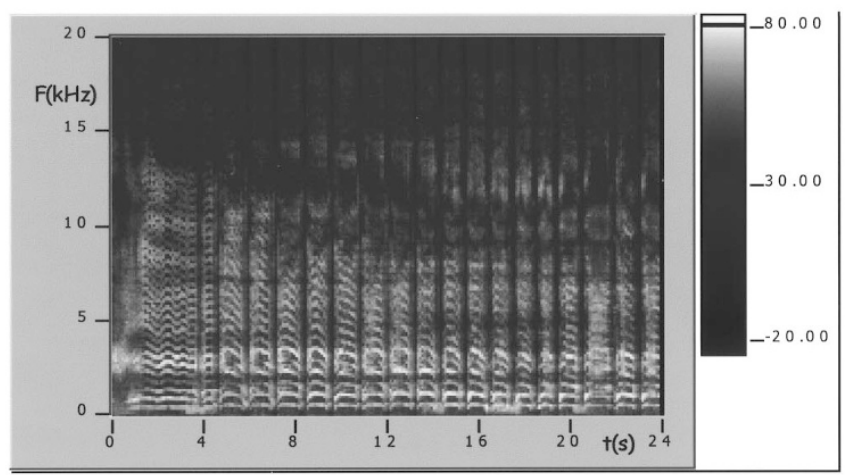

B)

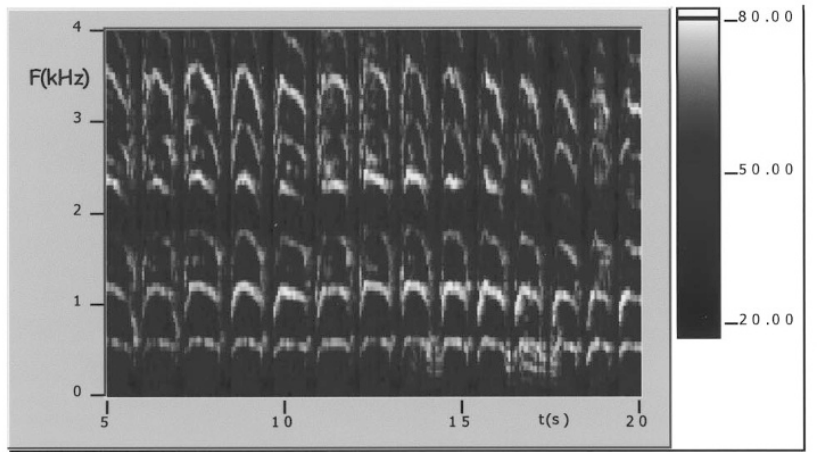

Figure 3. $A$, time-frequency crying intensity plot for a neonate with a DAN of 10. The intensity is represented by the brightness, with time on the horizontal axis and frequency on the vertical axis. The typical siren cry starts after $4 \mathrm{~s}$. Note the regular bursts of 1-s duration with harmonics up to 15-20 kHz. $B$, low-frequency detail of the time-frequency intensity plot of Fig. $3 A$, showing internal modulation of each cry burst (all frequencies vary) and spectral periodicity (note fundamental $\mathrm{F}_{0}$ and its multiple harmonics). The intensity scale has been changed to show more clearly the oscillating behavior of the frequency.

of 8 , even the first-cry pitch is different. The abrupt change in the slope of the plot of $F_{0}$ and DAN score, shown in Figure 2, also suggests the existence of a threshold at a DAN score of 8 , at which crying undergoes a qualitative change.

\section{CONCLUSIONS}

In conclusion, our results are indicative of a pain threshold at which cry features change. Thus, the acoustic features of crying help to discriminate between different degrees of pain. All well-developed neonatal pain scales are multifactorial, i.e. behavioral observation is combined with factors such as age, behavioral state, oxygen saturation, heart rate, and simultaneous observation of different parts of the body and face. These scales are good for research purposes, but are hardly suitable for clinical application: it is actually difficult to assess how painful a procedure is by a method that implies timing at least one variable (e.g. grimacing, crying, movements) and at the same time measuring changes in oxygen saturation or heart rate. This complex determination can only be done by filming



B)

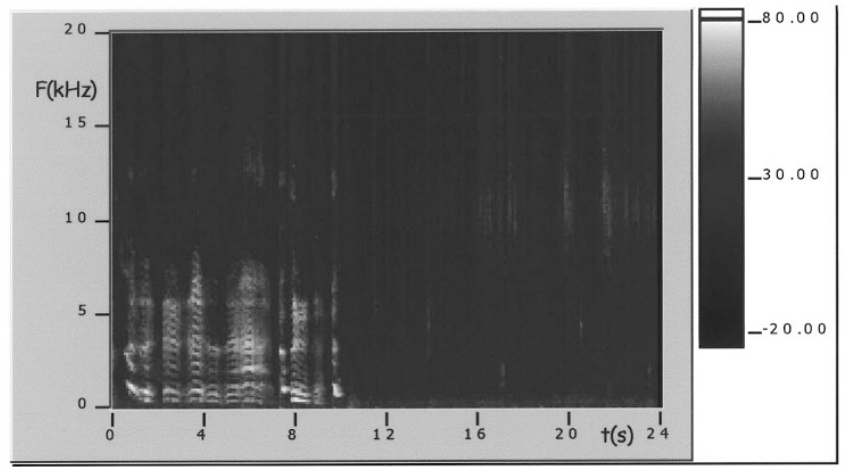

Figure 4. $A$, time-frequency crying intensity plot for a neonate with a DAN of 7. $B$, time-frequency crying intensity plot for a neonate with a DAN of 4 .

the procedure and measuring and scoring the variables later. This takes time and personnel. A simpler procedure is needed for clinical purposes. The three features of a baby's crying that we analyzed help to differentiate high-intensity and lowintensity pain: high-pitched, constantly loud, sirenlike crying occurs above a certain threshold. If pain intensity is lower, crying features are quite different. Operators can easily learn this difference. This may be useful during routine procedures.

\section{REFERENCES}

1. Barr RG, Hopkins B, Green JA 2000 Crying as a sign, a symptom and a signal: evolving concepts of crying behavior. In: Barr RG, Hopkins B, Green JA (eds) Crying as a Sign, a Symptom and a Signal. Cambridge University Press, Cambridge, pp 1-7 2. Choonara I 1999 Why do babies cry? BMJ 319:1381

3. Fuller BF 1991 Acoustic discrimination of three types of infant cries. Nurs Res 40:156-160

4. Gustafson GE, Wood RM, Green JA 2000 Can we hear the causes of infants' crying? In: Barr RG, Hopkins B, Green JA (eds) Crying as a Sign, a Symptom and a Signal. Cambridge University Press, Cambridge, pp 8-22

5. Porter FL, Miller RH, Marshall RE 1986 Neonatal pain cries: effect of circumcision on acoustic features and perceived urgency. Child Dev 57:790-802

6. Wood RM, Gustafson GE 2001 Infant crying and adults' anticipated caregiving responses: acoustic and contextual influences. Child Dev 72:1287-1300

7. Corwin MJ, Lester BM, Golub HL 1996 The infant cry: what can it tell us? Curr Probl Pediatr 26:325-334

8. Zeskind PS, Marshall TR 1988 The relation between variations in pitch and maternal perceptions of infant crying. Child Dev 59:193-196

9. Lester BM, Boukydis CF, Garcia-Coll CT, Peucker M, McGrath MM, Vohr BR, Brem F, Oh W 1995 Developmental outcome as a function of the goodness of fit 
between the infant's cry characteristics and the mother's perception of her infant's cry. Pediatrics 95:516-521

10. Stevens B, Johnston CC, Petryshen P, Taddio A 1996 Premature infant pain profile: developmental and initial validation. Clin J Pain 12:13-22

11. Grunau RVE, Oberlander TF, Holsti L 1998 Bedside application of the neonatal facial coding system in pain assessment of premature neonates. Pain 76:277-286

12. Lawrence J, Alcock D, McGrath P, Kay J, MacNurray SB, Dulberg C 1993 The development of a tool to assess neonatal pain. Neonatal Netw 12:59-66

13. Carbajal R, Paupe A, Hoenn E, Lenclen R, Olivier-Martin M 1997 DAN: une échelle comportamentale d'évaluation de la douleur aigue du nouveau-né [APN: evaluation behavioral scale of acute pain in newborn infants]. Arch Pediatr 4:623-628

14. Krechel SW, Bildner J 1995 CRIES: a new neonatal postoperative pain measurement score: initial testing of validity and reliability. Paediatr Anaesth 5:53-61

15. Sparshott M 1996 The development of a clinical distress scale for ventilated newborn infants: identification of pain based on validated behavioural scores. J Neonatal Nurs 2:5-11

16. Craig KD, Gilbert-Mac Leod CA, Lilley CM 2000 Crying as an indicator of pain in infants. In: Barr RG, Hopkins B, Green JA (eds) Crying as a Sign, a Symptom and a Signal. Cambridge University Press, Cambridge, pp 23-40

17. Bellieni CV, Bagnoli F, Perrone S, Nenci A, Cordelli DM, Fusi M, Ceccarelli S, Buonocore G 2002 The effect of multi-sensory stimulation on analgesia in term neonates: a randomized controlled trial. Pediatr Res 51:460-463

18. Bellieni CV, Buonocore G, Nenci A, Franci N, Cordelli DM, Bagnoli F 2001 Sensorial saturation: an effective tool for heel-prick in preterm infants. Biol Neonate 80:15-18

19. Carbajal R, Chauvet X, Couderc S, Olivier-Martin M 1999 Randomised trial of analgesic effects of sucrose, glucose, and pacifiers in term neonates. BMJ 319:13931397

20. Fort A, Manfredi C 1998 Acoustic analysis of newborn infant cry signals. Med Eng Phys 20:432-442

21. Hofer MA 2001 Infant crying: an evolutionary perspective. In: Barr RG, St JamesRoberts I, Keefe MR (eds) New Evidence on Unexplained Early Infant Crying: Its Origins, Nature and Management. Johnson \& Johnson Pediatric Institute, Calverton, NY, USA, pp 59-70

22. Wolff PH 1969 The natural history of crying and other vocalizations in early infancy. In: Foss B (ed) Determinants of Infant Behavior. Mathuen, London, pp 81-109

23. Valanne EH, Vuorenkoski V, Partanen TJ, Lind J, Wasz-Hockert O 1967 The ability of human mothers to identify the hunger cry signals of their own new-born infants during the lying-in period. Experientia 23:768-769
24. Wasz-Hockert O, Valanne E, Vuorenkoski V, Michelsson K, Sovijarvi A 1963 Analysis of some types of vocalization in the newborn and in early infancy. Ann Paediatr Fenn 9:1-10

25. Murray AD 1979 Infant crying as an elicitor of parental behavior: an examination of two models. Psychol Bull 86:191-215

26. Gustafson GE, Harris KL 1990 Women's responses to young infants' cries. Dev Psychol 26:144-152

27. Abu-Saad HH, Bours GJJ, Stevens B, Hamers PH 1998 Assessment of pain in the neonate. Semin Perinatol 22:402-416

28. Fuller BF, Horii Y 1986 Differences in fundamental frequency, jitter, and shimmer among four types of infant vocalizations. J Commun Disord 19:441-447

29. Runefors P, Arnbjornsson E, Elander G, Michelsson K 2000 Newborn infants' cry after heel-prick: analysis with sound spectrogram. Acta Paediatr 89:68-72

30. Goberman AM, Robb MP 1999 Acoustic examination of preterm and full-term infant cries: the long-time average spectrum. J Speech Lang Hear Res 42:850-861

31. Robb MP, Cacace AT 1995 Estimation of formant frequencies in infant cry. Int J Pediatr Otorhinolaryngol 32:57-67

32. Cacace AT, Robb MP, Saxman JH, Risemberg H, Koltai P 1995 Acoustic features of normal-hearing pre-term infant cry. Int J Pediatr Otorhinolaryngol 33:213-224

33. Zeskind PS, Sale J, Maio J, Huntington L, Weiseman JR 1985 Adult perceptions of pain and hunger cries: a synchrony of arousal. Child Dev 56:549-554

34. Xie Q, Ward RK, Laszlo CA 1996 A hidden Markov model method for estimating normal infants distress levels from their cry sounds. IEEE Trans Speech Audio Processing 4:253-265

35. Johnston CC, Sherrard A, Stevens B, Franck L, Stremler R, Jack A 1999 Do cry features reflect pain intensity in pre-term neonates? Biol Neonate 76:120-124

36. Johnston CC, Strada ME 1986 Acute pain response in infants: a multidimensional description. Pain 24:373-382

37. Michelsson K, Jarvenpaa AL, Rinne A 1983 Sound spectrographic analysis of pain cry in preterm infants. Early Hum Dev 8:141-149

38. Robb MP, Goberman AM, Cacace AT 1997 An acoustic template of newborn infant crying. Folia Phoniatr Logop 49:35-41

39. Wiedenmann G, Todt D 1990 Discrete responses of adult subjects during the exposure to infant crying sequences. Early Child Dev Care 65:179-188

40. Michelsson K, Raes J, Thoden C, Wasz-Hockert O 1982 Sound spectrographic cry analysis in neonatal diagnostics: an evaluative study. J Phonet 10:9-88

41. Zeskind P, Lester B 1981 Analysis of cry features in newborns with differential fetal growth. Child Dev 52:207-212

42. Green JA, Gustafson GE, McGhie AC 1998 Changes in infants' cries as a function of time in a cry bout. Child Dev 69:271-279 